\title{
Influence of Early Social Learning on Later Feeding Behaviour for Novel Food in Calves
}

\author{
Michiru FUKASAWA, Shusuke SATO and Kazuo SUGAWARA \\ Graduate School of Agricultural Science, Tohoku University, Sendai-shi, Aoba-ku 981-8555, Japan
}

(Received September 9, 1998 ; Accepted May 14, 1999)

\begin{abstract}
The object of this study is to examine whether the early social learning experience influences later intake of three novel foods in calves. This study consisted of two phases : the learning period and the persistent testing period. In the learning period, Group I of six calves were exposed to novel food and ate together with their dams. Group $O$ of six calves could see what their dams ate, but they could not eat the novel food. Group $\mathrm{T}$ of six calves were exposed to novel food alone. The novel foods used in this experiment were alfalfa haycubes which their dams had eaten before, and tofu lees which their dams had not previously experienced eating. The learning period to the novel food lasted for three days in each group. After the learning period, calves were weaned and fed on a basal diet for 12 weeks as the persistence period of learning. Intake of alfalfa haycubes tended to increase in Group $I$ at almost significant level $(P=0.05)$. Intake of tofu lees did not differ significantly among the three groups. Early social learning on novel food, even for only $60 \mathrm{~min}$, influenced feeding behaviour after 12 weeks in calves.

Animal Science Journal 70 (5) : 356-359, 1999
\end{abstract}

Key Words : Cattle, Imitation, Observational learning, Novelty, Experience

Social learning can occur either with immediate reinforcement or with delayed reinforcement ${ }^{14)}$. Social learning with immediate reinforcement is called imitational learning ${ }^{8)}$. Imitational learning has been demonstrated in monkeys ${ }^{6)}$ and rats $^{5)}$. Social learning with delayed reinforcement is generally considered to be observational learning ${ }^{10)}$. Observational learning has been demonstrated in cats ${ }^{3)}$ and primates ${ }^{9)}$.

A previous paper ${ }^{4)}$ suggested that the existence of cattle which had experienced grazing brings psychological stability and social learning to unexperienced calves under the grazing situation. According to the previous study, calves with heifers or cows grazed more efficiently than calves alone. Many studies using sheep ${ }^{1,2,7,12,13)}$ suggested that social learning sustained longer than trial and error even if the young were separated from social models after learning. In the modern intensive animal production, novel foods such as food processing by-products, animal origin foods and woods are commonly presented to animals.
From the view of reducing stress and accelerating intakes, it is an important technique for animal production to make animals adapt to new foods smoothly.

The object of this study was to examine whether the early social learning experience in cattle influences the future intake of novel food in calves. This paper also discussed whether imitation or observation is more important in social learning.

\section{Materials and Methods}

This study took place from October 1996 to January 1997 at the Experimental Farm of Tohoku University. This experiment was divided into two phases, the learning period and the persistent testing period. Eighteen Japanese Black calves with their dams were assigned to three groups according calves' weight and sex (Table 1). All calves were bone at June and July, 1996. The first group of six calves was an imitation model (I), the second group of six calves was an observation model $(\mathrm{O})$, and the third group of six

Corresponding : Michiru FUKASAWA (fax : +81 (0) 22-717-8697, e-mail : fuka@bios.tohoku.ac.jp)

Anim. Sci. J. 70 (5): 356-359, 1999 
calves was a trial and error model ( $T$ ). In the learning period, Group I were exposed to novel food with their dams and they ate together from same trough. Group $\mathrm{O}$ were separated from their dams by fencing, who were eating novel food. The calves could see what their dams ate, but they could not eat the novel food. Group $T$ were separated from their dams by fencing, and exposed to novel foods alone.

Each group with dams was kept in a separate pen

Table 1. The number and body weight $(\mathrm{kg})$ of calves in the learning period and testing period of each treatment

\begin{tabular}{|c|c|c|c|}
\hline Group & $\mathrm{n}$ & $\begin{array}{l}\text { Learning } \\
(16-20)^{* 1}\end{array}$ & $\begin{array}{l}\text { Testing } \\
(28-32)\end{array}$ \\
\hline Group I & $\sigma^{7}: 3$ 우: 3 & $\begin{array}{c}87 \pm 21 * 2 \\
(452 \pm 51)^{* 3}\end{array}$ & $144 \pm 41$ \\
\hline Group O & $\sigma^{7}: 3$ 우: 3 & $\begin{array}{c}85 \pm 12 \\
(422 \pm 51)\end{array}$ & $145 \pm 23$ \\
\hline Group T & $0^{x}: 3$ 早: 3 & $\begin{array}{c}86 \pm 15 \\
(441 \pm 19)\end{array}$ & $143 \pm 18$ \\
\hline
\end{tabular}

*1 Weeks of age.

${ }^{* 2}$ Mean tstandard deviation.

*3 Dams' weight. and fed grass silage, corn silage and formula feeds as a basal diet throughout the experiment. The novel foods used in this experiment were alfalfa haycubes which their dams had previously experienced eating, and tofu lees which their dams had not previously experienced. Calves had eaten neither of the novel foods.

The learning period of each novel food started when calves were 16-20 weeks old and lasted for three days in each group. Calves in each group were exposed to each food for $20 \mathrm{~min}$ per day just before the ordinary feeding time. Food (fresh weight) proportional to about $0.1 \%$ of total body weight was available. These calves were weaned three days after the learning period and separated into three groups at random.

After the learning period,calves were fed a basal diet for 12 weeks. Persistent effects of the treatment were tested, when calves were 28-32 weeks old. Calves were individually given each food once $(1.5 \mathrm{~kg}$ of fresh weight : about $1 \%$ of mean body weight) for $20 \mathrm{~min}$ and the amount ingested in grams was recorded.

The intake was compared by analysis of variance (GLM procedure ; Statistical Analysis Systems Insti-

Table 2. The amount offered and intake of two foods in the learning period of each treatment

\begin{tabular}{|c|c|c|c|}
\hline $\begin{array}{l}\text { Treatment*! } \\
\text { Animals measured }\end{array}$ & Group I + dams & $\stackrel{\text { O }}{\text { Dams Group O }}$ & $\stackrel{\mathrm{T}}{\text { Group } \mathrm{T}}$ \\
\hline \multicolumn{4}{|l|}{ Alfalfa haycubes } \\
\hline Amount of feeding $(\mathrm{kg})$ & 25.00 & 20.00 & 5.00 \\
\hline \multicolumn{4}{|l|}{ Intake (kg) } \\
\hline $96 / 10 / 30^{* 2}$ & 14.55 & 11.79 & 0.07 \\
\hline $10 / 31$ & 13.64 & 12.28 & 0.11 \\
\hline $11 / 01$ & 18.33 & 12.40 & 0.75 \\
\hline \multicolumn{4}{|l|}{ Tofu lees } \\
\hline Amount of feeding $(\mathrm{kg})$ & 25.00 & 20.00 & 5.00 \\
\hline \multicolumn{4}{|l|}{ Intake $(\mathrm{kg})$} \\
\hline $96 / 10 / 30$ & 0.49 & 0.15 & 0.05 \\
\hline $10 / 31$ & 0.37 & 0.49 & 0.05 \\
\hline $11 / 01$ & 0.33 & $* 3$ & 0.02 \\
\hline
\end{tabular}

${ }^{* 1}$ Treatment I show values per unit of dam + calf and the others per unit animal.

*2 Date observed.

${ }^{3}$ No data. 


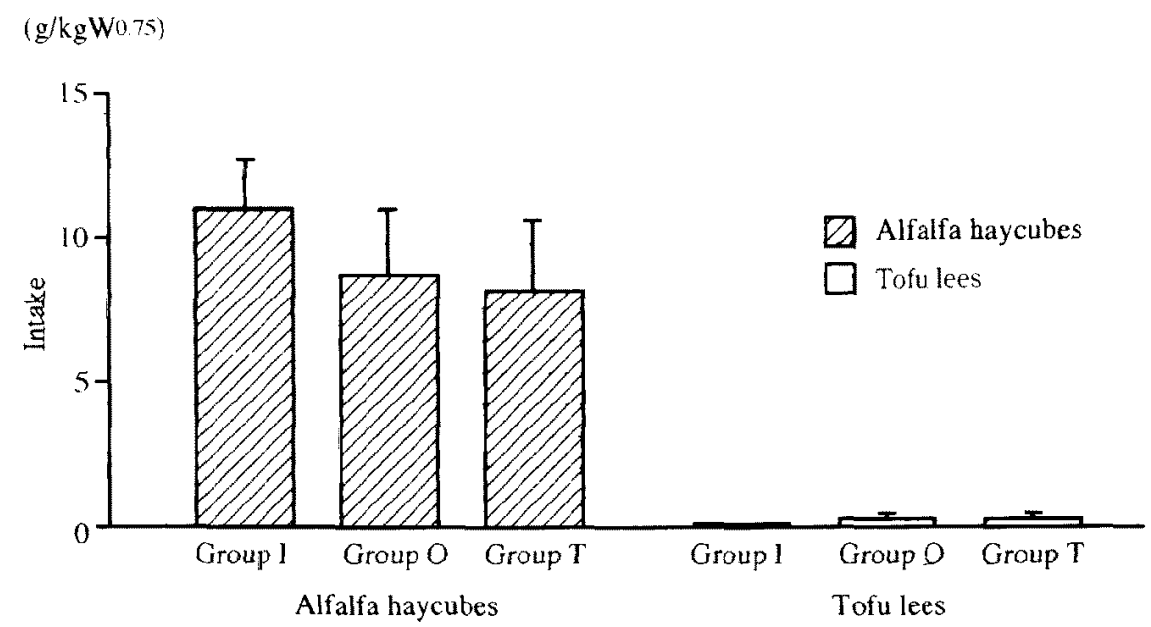

Fig. 1. Intake per $20 \mathrm{~min}$ of two foods in the testing period for each group Each column and error ber represent mean and standard deviation, respectively.

tute Inc., 1997) in which the effect of the group was used as a fixed effect.

\section{Results and Discussion}

Intake of alfalfa haycubes and tofu lees in the learning period of each groups shown in Table 2. During the learning period, dams of Group I smelled the alfalfa haycubes and ate immediately. Group I watched their dams eating, and participated immediately. On the other hand, dams of Group I smelled tofu lees and ate little by little, but calves hardly ate any tofu lees. Dams of Group $\mathrm{O}$ behaved in the same manner as dams of Group I, and Group $O$ watched their dams eating. Group $T$ smelled alfalfa haycubes and tofu lees and ate little by little. Tofu lees, which the dams had not previously experienced, were scarcely eaten by the calves in all groups even in the learning period. Provenza and Balph ${ }^{11}$ suggested that the existence of the experienced animal reduced the novelty of the food. In this study, it was thought that social learning of novel food occurred only under eating of alfalfa haycubes not under eating of tofu lees.

The intake of each food in the testing period is shown in Fig 1. Group I ate alfalfa haycubes immediately, but Group $\mathrm{O}$ and $\mathrm{T}$ smelled alfalfa haycubes and ate little by little. The effect of the group on intake of alfalfa was almost significant (F 2, 15 $=2.57$,
$P=0.11)$. Group I tended to eat more effectively than Groups $O$ and $T$ (vs Group $O ; P=0.10$, vs Group $\mathrm{T} ; \mathrm{P}=0.05$ ) and there was no significant difference between Group $O$ and Group T. Intakes of tofu lees, however, did not differ significantly among all three groups. Intake of tofu lees was too little, and four individuals of Group I, two of Group $\mathrm{O}$ and three of Group $T$ did not eat at all in the testing pcriods.

There were no differences in the intake of each food by Group $\mathrm{O}$ and Group T. Labot et al. ${ }^{7)}$ suggested that familiarity with the novel food by sight played an important role in acceptance of the novel food. In this experiment, however, the intake of the novel food did not improve by observation only. Thohallsdottir et al. ${ }^{14)}$ reported immediate repetition enhanced the effect of observational learning. As there were 12 weeks between the learning period and the testing period in this study, observational learning did not occur or learning disappeared before the testing period under the usual feeding condition.

The intake of calves was improved by social learning with experienced dams, even for only $60 \mathrm{~min}$ during the nursing period. Observational learning did not prove to be effective for the learning of novel food. It is suggested that imitational learning improved the acceptance of novel food more efficiently than observational learning. 


\section{Acknowledgement}

The authors are grateful to Mr. Y. Yashima and the staff of the Experimental Farm of Tohoku University for their technical assistance.

\section{References}

1) Chapple RS, Wodzicka-Tomaszewska M,Lynch JJ. The learning behaviour of sheep when introduced to wheat. I. Social transmission of wheat feeding and the role of sense. Applied Animal Behaviour Science, $18: 163-172.1987$.

2) Chapple RS, Wodzicka-Tomaszewska M. The learning behaviour of sheep when introduced to wheat. II. Wheat acceptance by sheep and the effects of trough familiarity. Applied Animal Behaviour Science, 18 : 157-162. 1987.

3) Chesler P. Maternal influence in learning by observation in kittens. Science, $166: 901-903.1969$.

4) Fukasawa M, Sato S, Nishiwaki A, Sugawara K. The influence of experienced cattle on calf grazing in the pasture. Animal Science Journal, 70 : 74-80. 1999.

5) Galef BG Jr. Studies of social learning in Norway rats : a brief review. Developmental Psychobiology, 15 : 279-295. 1982.

6) Kawai M. Newly-acquired pre-cultural behaviour of natural troop of Japanese monkeys on Koshima Islet. Primates, 6:1-30. 1965.

7) Lobato JFP, Pearce GR,Beilharz RG. Effects of early familiarization with dietary supplements on the subsequent ingestion of molasses-urea blocks by sheep. Applied Animal Ethology, 6 : 149-161. 1980.

8) Michael D. Imitation. In The Oxford dictionary of animal behavior. (Mcfarland $\mathrm{D}$ ed.) 716722 . Doubutusha. Tokyo. 1993. (in Japanese ; translated by Kimura T.)

9) Myerd WA. Observational learning in monkeys. Journal of the Experimental Analysis of Behavior, 14 : 225-235. 1970.

10) Pallaud B. Hypotheses on mechanisms underlying observational learning in animals. Behavioural Processes, 9 : 381-394, 1984.

11) Provenza FD, Balph DF. Diet learning by domestic ruminants : theory, evidence, and practical implications. Applied Animal Behaviour Science, 18:211232. 1987.

12) Sarwat NM, Provenza FD. Effects of age and conditions of exposure on maternally mediated food selection by lambs. Applied Animal Behaviour Science, 33 : 35-42. 1992.

13) Sarwat NM, Provenza FD. Preference of the mother affects selection and avoidance of foods by lambs differing in age. Applied Animal Behaviour Science, 28 : 255-263. 1990

14) Thorhallsdottir AG, Provenza FD, Balph DF. Ability of lambs to learn about novel foods while observing or participating with social models. Applied Animal Behaviour Science, 25 : 25-33. 1990. 